\title{
Clinical characteristics, treatment methods and prognoses of patients with oral squamous cell carcinoma in Japanese population: a single institution retrospective cohort study
}

Chonji Fukumoto ${ }^{1 *}$ D, Shouhei Ogisawa ${ }^{1}$, Masashi Tani ${ }^{1}$, Toshiki Hyodo ${ }^{1}$, Ryouta Kamimura ${ }^{1}$, Yuta Sawatani ${ }^{1}$, Tomonori Hasegawa' ${ }^{1}$, Yuske Komiyama ${ }^{1,2}$, Atsushi Fujita ${ }^{1}$, Takahiro Wakui ${ }^{1}$, Yasuo Haruyama ${ }^{3}$, Gen Kobashi ${ }^{3}$ and Hitoshi Kawamata ${ }^{1}$

\begin{abstract}
Background: The status of oral cancer therapy in elderly patients in Japan, where ageing is rapidly progressing, may serve as a model for other countries with similar demographics. There is controversy over what kind of treatment should be applied and how aggressively it should be applied to very elderly patients who have exceeded the average life expectancy. Given that 85 years is approximately the overall Japanese life expectancy at birth, we considered a threshold of 85 years and hypothesized that the prognosis of oral squamous cell carcinoma (SCC) patients aged $\geq 85$ years was not inferior to that of those $<85$ years. The aim of the present study was to investigate the clinical characteristics, treatment methods, and prognoses of Japanese oral SCC patients aged $\geq 85$ years.

Methods: A retrospective cohort study was performed. The data of patients with primary oral SCC $(n=358)$ from 2005 to 2018 in our institute were extracted from electronic medical records. A total of 358 patients with oral SCC were divided into two groups ( $\geq 85$ years group $[n=26]$ and $<85$ years group $[n=332]$ ) based on the age threshold of 85 years at the first visit. Kaplan-Meier survival analyses and Cox proportional hazard models were used to analyse overall survival (OS) and hazard ratios (HRs) according to age group, treatment, and TNM classification.

\footnotetext{
* Correspondence: chonji-f@dokkyomed.ac.jp

${ }^{1}$ Department of Oral and Maxillofacial Surgery, Dokkyo Medical University School of Medicine, 880 Kitakobayashi, Mibu, Shimo-Tsuga, Tochigi 321-0293, Japan

Full list of author information is available at the end of the article
}

(c) The Author(s). 2020 Open Access This article is licensed under a Creative Commons Attribution 4.0 International License, which permits use, sharing, adaptation, distribution and reproduction in any medium or format, as long as you give appropriate credit to the original author(s) and the source, provide a link to the Creative Commons licence, and indicate if changes were made. The images or other third party material in this article are included in the article's Creative Commons licence, unless indicated otherwise in a credit line to the material. If material is not included in the article's Creative Commons licence and your intended use is not permitted by statutory regulation or exceeds the permitted use, you will need to obtain permission directly from the copyright holder. To view a copy of this licence, visit http://creativecommons.org/licenses/by/4.0/ The Creative Commons Public Domain Dedication waiver (http://creativecommons.org/publicdomain/zero/1.0/) applies to the data made available in this article, unless otherwise stated in a credit line to the data. 
(Continued from previous page)

Results: There was no difference in the 5 -year OS rate between the $\geq 85$ years and $<85$ years groups ( $80.8 \%$ vs. $82.2 \%, P=0.359)$. This finding was the same in the operative ( $94.7 \%$ vs. $85.8 \%, P=0.556)$ and non-operative $(42.9 \%$ vs. $33.2 \%, P=0.762)$ groups, indicating that age did not affect prognosis. Mortality was lower in the operative group than in the non-operative group (adjusted HR: $0.276,95 \% \mathrm{Cl}: 0.156-0.489, P<0.001$ ), suggesting that surgery is a superior method. However, non-surgical treatment was selected at a higher rate in the $\geq 85$ years group (26.9\% vs. $11.1 \%, P=0.028)$.

Conclusions: This study suggests the prognosis of $\geq 85$-year-old patients was not inferior to that of < 85-year-old patients. We recommend that surgery as the first choice treatment for $\geq 85$-year-old patients with oral SCC who can tolerate surgery should be performed.

Keywords: Oral cancer, Squamous cell carcinoma, Elderly patient, Surgery, Overall survival

\section{Background}

The number of new cases of oral cancer each year exceeds 350,000 worldwide, and the cumulative risk in those under the age of 75 was reported to be 0.46 in 2018 [1]. Oral cancer develops in the tongue, mandibular gingiva, maxillary gingiva, buccal mucosa, hard palate, oral floor and lips [2]. Most oral cancers are histologically diagnosed as squamous cell carcinomas (SCCs), because the surface of oral mucosa consists of squamous epithelium. However, salivary gland tumours, malignant lymphomas, malignant melanomas, and mesenchymal tumours may also develop in oral cavity [2]. Surgery is mainly performed for the treatment of oral SCCs and sometimes combined with chemotherapy (including molecular targeted treatment), immune checkpoint inhibitor therapy and radiation. These treatments have considerably improved overall survival (OS) and progression-free survival (PFS) in patients with oral SCCs. However, some patients have shown local recurrence, cervical lymph node metastasis, or distal metastasis after the initial treatment, and it is difficult to achieve complete cure in such patients.

Japan currently has the highest life expectancy $(84.2$ years old: male: 81.1 , female: 87.1 ) and healthy life expectancy (74.8 years old) at birth worldwide [3, 4]. People aged $\geq 65$ years accounted for $26.0 \%$ of the total Japanese population in 2015 [3], and this is estimated to increase to $36.4 \%$ by 2050 [3]. Thus, the number of elderly patients with oral cancer are likely to increase in Japan; this situation may serve as a model for other countries with ageing populations. In fact, the number of oral SCC patients at our institution has increased annually since it was opened in 1974, and the age distribution shows an increasing trend (Supplemental Figure 1A and B). In many reports and reviews focused on elderly patients with different types of cancers, those aged 65 , 70 , or 75 years old or older were regarded as elderly [510]. However, a detailed investigation of patients aged over 85 years old with oral cancer has not been reported.
In clinical practice, it can be difficult to select aggressive treatment methods for elderly patients who have exceeded the average life expectancy. In general, radical treatment should be applied whenever possible, even in elderly patients. Currently, people aged over 85 years have achieved the overall Japanese life expectancy at birth [4], but clinical evidence to guide treatment choices in patients with SCC aged over 85 years is insufficient. Therefore, we hypothesized that the prognosis of oral cancer patients aged 85 years and older is not inferior to that of those under 85 years. Based on this hypothesis, we performed this study to investigate the clinical characteristics, treatment methods and prognoses of patients aged $\geq 85$ years old with oral SCC in Japan.

\section{Methods \\ Data sources}

This study was a retrospective cohort study. The review period was from April 2005 to December 2018 at the Department of Oral and Maxillofacial Surgery, Dokkyo Medical University School of Medicine. The data were obtained from electronic medical records. The design of this study was approved by the Medical Ethical Research Committee of Dokkyo Medical University Hospital (approval ID R-22-12 J).

\section{Patients}

The data of patients with primary oral SCC $(n=358)$ were collected during the review period. Treatments and prognoses were retrospectively examined according to electronic medical records. Based on the threshold of 85 years, which is approximately the average life expectancy in Japan, the patients were divided into two groups by age at first visit. In this study, patients aged $\geq 85$ years at the time of the first visit were defined as the " $\geq 85$ years group", and the patients aged $<85$ years were designated as the " $<85$ years group" for comparison. 


\section{Exposures and potential confounders}

Age, sex, primary site, disease stage, and treatment methods, which were considered exposures, and potential confounding factors were investigated, and death or survival with recurrence/metastasis were considered outcomes. The cancer stage was classified using the International Union Against Cancer (UICC) TNM Classification of Malignant Tumours, 8th edition [2].

\section{Statistical analysis}

Descriptive analyses were performed to assess demographics and clinical factors in the 358 patients with oral SCC at baseline. A chi-squared test or Fisher's exact test was used to compare each categorical variable between the $\geq 85$ years and $<85$ years groups. The 5 -year OS and disease-free survival (DFS) rates were analysed in all patients with or without operations and in the two age groups using Kaplan-Meier survival analyses. To obtain hazard ratios (HRs) for mortality and related factors (male vs female, $\geq 85$ years vs. $<85$ years, $\mathrm{T}$ stage: $\mathrm{T} 3+$ T4a + T4b vs. Tis $+\mathrm{T} 1+\mathrm{T} 2, \mathrm{~N}$ stage: $\mathrm{N} 1+\mathrm{N} 2 \mathrm{a}+\mathrm{N} 2 \mathrm{~b}+$ $\mathrm{N} 3 \mathrm{a}+\mathrm{N} 3 \mathrm{~b}$ vs. N0, and operation vs. non-operation), univariate analyses and a multivariable analysis were performed with a Cox proportional hazard model. Twotailed $P$ values of $<0.05$ were considered to be significant. IBM SPSS ver. 24.0 (IBM SPSS, Inc., Tokyo, Japan) was used for the statistical analyses.

\section{Results}

\section{Characteristics and treatment methods of patients with} oral SCC

The characteristics and treatment methods of the patients with oral SCC in our institute are shown in Table 1. There were 358 patients included in 207 males (57.8\%) and 151 females (42.3\%), and their average of age (SD) was 66.1 (14.3) years old. Of the 358 patients, 26 patients were aged $\geq 85$ years at the time of the first visit and were defined as the $\geq 85$ years group, and 332 patients were aged $<85$ years and were designated as the $<85$ years group for comparisons in further analysis. The primary site, $\mathrm{T}$ stage, $\mathrm{N}$ stage, $\mathrm{M}$ stage and clinical TNM stage for all patients are shown in Table 1. Most of the patients were treated by operative methods $(87.7 \%)$ with or without chemotherapy and/or radiation. Some patients were treated by non-operative methods (12.3\%), probably because of the patients' intentions or local and systemic limitations for surgery.

\section{Comparisons of the characteristics, treatment methods,} and prognoses of patients with oral SCC by age ( $\geq 85$ years or $<85$ years)

Table 2 shows that the percentage of females was significantly higher than that of males in the $\geq 85$ years group $(P=0.001)$. The tongue as the primary site occurred
Table 1 Characteristics of patients with oral SCC $(n=358)$

\begin{tabular}{|c|c|}
\hline Sex, male, n (\%) & $207(57.8)$ \\
\hline Age, mean (SD) y & $66.1(14.3)$ \\
\hline \multicolumn{2}{|l|}{ Age group, n (\%) } \\
\hline$<85 y$ & $332(92.7)$ \\
\hline$\geq 85 y$ & $26(7.3)$ \\
\hline \multicolumn{2}{|l|}{ Primary site, $n(\%)$} \\
\hline Tongue & $177(49.4)$ \\
\hline Lower gingiva & $71(19.8)$ \\
\hline Upper gingiva & $47(13.1)$ \\
\hline Buccal mucosa & $31(8.7)$ \\
\hline Oral floor & $22(6.1)$ \\
\hline Lip & $4(1.1)$ \\
\hline Palate & $6(1.7)$ \\
\hline \multicolumn{2}{|l|}{ T stage, $n(\%)$} \\
\hline Tis & $15(4.2)$ \\
\hline $\mathrm{T} 1$ & $49(13.7)$ \\
\hline $\mathrm{T} 2$ & $88(24.6)$ \\
\hline T3 & $75(20.9)$ \\
\hline $\mathrm{T} 4 \mathrm{a}$ & $123(34.4)$ \\
\hline $\mathrm{T} 4 \mathrm{~b}$ & $8(2.2)$ \\
\hline \multicolumn{2}{|l|}{ N stage, $n(\%)$} \\
\hline No & $257(71.8)$ \\
\hline N1 & $31(8.7)$ \\
\hline $\mathrm{N} 2 \mathrm{~b}$ & $33(9.2)$ \\
\hline $\mathrm{N} 2 \mathrm{C}$ & $11(3.1)$ \\
\hline N3b & $26(7.3)$ \\
\hline \multicolumn{2}{|l|}{ M stage, $n(\%)$} \\
\hline MO & $357(99.7)$ \\
\hline M1 & $1(0.3)$ \\
\hline \multicolumn{2}{|l|}{ Stage, $n(\%)$} \\
\hline Stage 0 & $21(5.9)$ \\
\hline Stage 1 & $46(12.1)$ \\
\hline Stage 2 & $74(20.7)$ \\
\hline Stage 3 & $69(19.3)$ \\
\hline Stage $4 a$ & $116(32.4)$ \\
\hline Stage $4 b$ & $31(8.7)$ \\
\hline Stage $4 c$ & $6(0.3)$ \\
\hline \multicolumn{2}{|l|}{ Treatment, $\mathrm{n}(\%)$} \\
\hline Operative treatment & $314(87.7)$ \\
\hline Surgery only & $225(71.7)$ \\
\hline Surgery and postoperative chemotherapy & $52(16.6)$ \\
\hline Surgery and postoperative radiation & $6(1.9)$ \\
\hline Surgery and postoperative chemoradiation & $31(9.9)$ \\
\hline Non-operative treatment & $44(12.3)$ \\
\hline Chemotherapy & $3(6.8)$ \\
\hline Radiation & $13(29.5)$ \\
\hline Chemoradiation & $28(63.6)$ \\
\hline
\end{tabular}


Table 2 Comparison of the characteristics, treatment methods, and prognoses of patients with oral SCC by age

\begin{tabular}{|c|c|c|c|}
\hline & $\begin{array}{l}\text { Age }<85 \text { years group } \\
(n=332)\end{array}$ & $\begin{array}{l}\text { Age } \geq 85 \text { years group } \\
(n=26)\end{array}$ & $P$ value $^{\mathrm{a}}$ \\
\hline \multicolumn{4}{|l|}{ Sex, n(\%) } \\
\hline Female & $132(39.8)$ & $19(73.1)$ & 0.001 \\
\hline Male & $200(60.2)$ & $7(26.9)$ & \\
\hline \multicolumn{4}{|l|}{ Primary site, $n(\%)$} \\
\hline Tongue & $171(51.5)$ & $6(23.1)$ & 0.005 \\
\hline Other ${ }^{c}$ & $161(48.5)$ & $20(76.9)$ & \\
\hline \multicolumn{4}{|l|}{ T stage, $\mathrm{n}(\%)$} \\
\hline $\mathrm{Tis}+\mathrm{T} 1+\mathrm{T} 2$ & $146(44.0)$ & $6(23.1)$ & 0.038 \\
\hline $\mathrm{T} 3+\mathrm{T} 4 \mathrm{a}+\mathrm{T} 4 \mathrm{~b}$ & $186(56.0)$ & $20(76.9)$ & \\
\hline \multicolumn{4}{|l|}{$\mathrm{N}$ stage, $\mathrm{n}(\%)$} \\
\hline NO & $234(70.5)$ & $23(88.5)$ & 0.050 \\
\hline $\mathrm{N} 1+\mathrm{N} 2 \mathrm{a}+\mathrm{N} 2 \mathrm{~b}+\mathrm{N} 3 \mathrm{a}+\mathrm{N} 3 \mathrm{~b}$ & $98(29.5)$ & $3(11.5)$ & \\
\hline \multicolumn{4}{|l|}{ M stage, n(\%) } \\
\hline Mo & $332(100.0)$ & $25(96.2)$ & $0.073^{b}$ \\
\hline M1 & $0(0.0)$ & $1(3.8)$ & \\
\hline \multicolumn{4}{|l|}{ Stage, $n(\%)$} \\
\hline Stage $1+2$ & $135(40.7)$ & $6(23.1)$ & 0.077 \\
\hline Stage $3+4 a+4 b+4 c$ & $197(59.3)$ & $20(76.9)$ & \\
\hline \multicolumn{4}{|l|}{ Treatment, n(\%) } \\
\hline Non-operative treatment & $37(11.1)$ & $7(26.9)$ & $0.028^{b}$ \\
\hline Operative treatment & $295(88.9)$ & $19(73.1)$ & \\
\hline \multicolumn{4}{|l|}{ Recurrence or metastasis ${ }^{d}$} \\
\hline No & $228(77.3)$ & $17(89.5)$ & $0.170^{b}$ \\
\hline Yes & $67(22.7)$ & $2(10.5)$ & \\
\hline \multicolumn{4}{|l|}{ Death in 5 years period } \\
\hline No & $273(82.2)$ & $21(80.8)$ & $0.511^{b}$ \\
\hline Yes & 59 (17.8) & 5 (19.2) & \\
\hline
\end{tabular}

${ }^{a}$ Chi-squared test

${ }^{\mathrm{b}}$ Fisher's exact test

c Other primary sites included the lower gingiva, upper gingiva, buccal mucosa, oral floor, lip, and palate

${ }^{d}$ Recurrence or metastasis unknown $(n=44)$ and excluded

significantly less frequently in the $\geq 85$ years group than in the $<85$ years group $(6 / 26,23.1 \%$ vs. $171 / 332,51.5 \%$, $P=0.005)$. Regarding TNM classification, in the $\geq 85$ years group, significantly more patients had stage T3 or more advanced disease than stage $\mathrm{T} 2$ or earlier stage disease $(P=0.038)$. Regarding $\mathrm{N}$ classification, the rate of cervical lymph node metastasis was significantly higher in the $\geq 85$ years group than in the $<85$ years group $(P=$ 0.050 ). Thus, many $\geq 85$ years patients had stage III or higher, but the difference was not significant $(P=0.077)$.

Non-surgical treatments (Table 2) were performed in $7(26.9 \%)$ patients in the $\geq 85$ years group and in 37 (11.1\%) patients in the $<85$ years group, respectively. These data show that surgery was significantly less frequently performed in the $\geq 85$ years group $(P=0.028)$.
OS immediately after treatment initiation was shorter in the $\geq 85$ years group, but the 5 -year OS did not differ significantly between the $\geq 85$ years and $<85$ years groups ( $80.8 \%$ vs. $82.2 \%, P=0.359$; Fig. 1$)$. OS $(94.7 \%$ vs. $85.8 \%$, $P=0.556$; Fig. 2$)$ and DFS (89.5\% vs. $77.3 \%, P=0.509$; Fig. 3) in the surgery subgroup and OS in the nonsurgery subgroup $(42.9 \%$ vs. $33.2 \%, P=0.762$; Fig. 4$)$ did not differ significantly between the $\geq 85$ years and $<85$ years groups. The maximum follow-up period was 42 months in the $\geq 85$ years group.

\section{Associations of mortality due to oral SCC with several factors}

The mortality (Table 3 ) did not differ significantly in the $\geq 85$ years and $<85$ years groups in the univariate analysis 


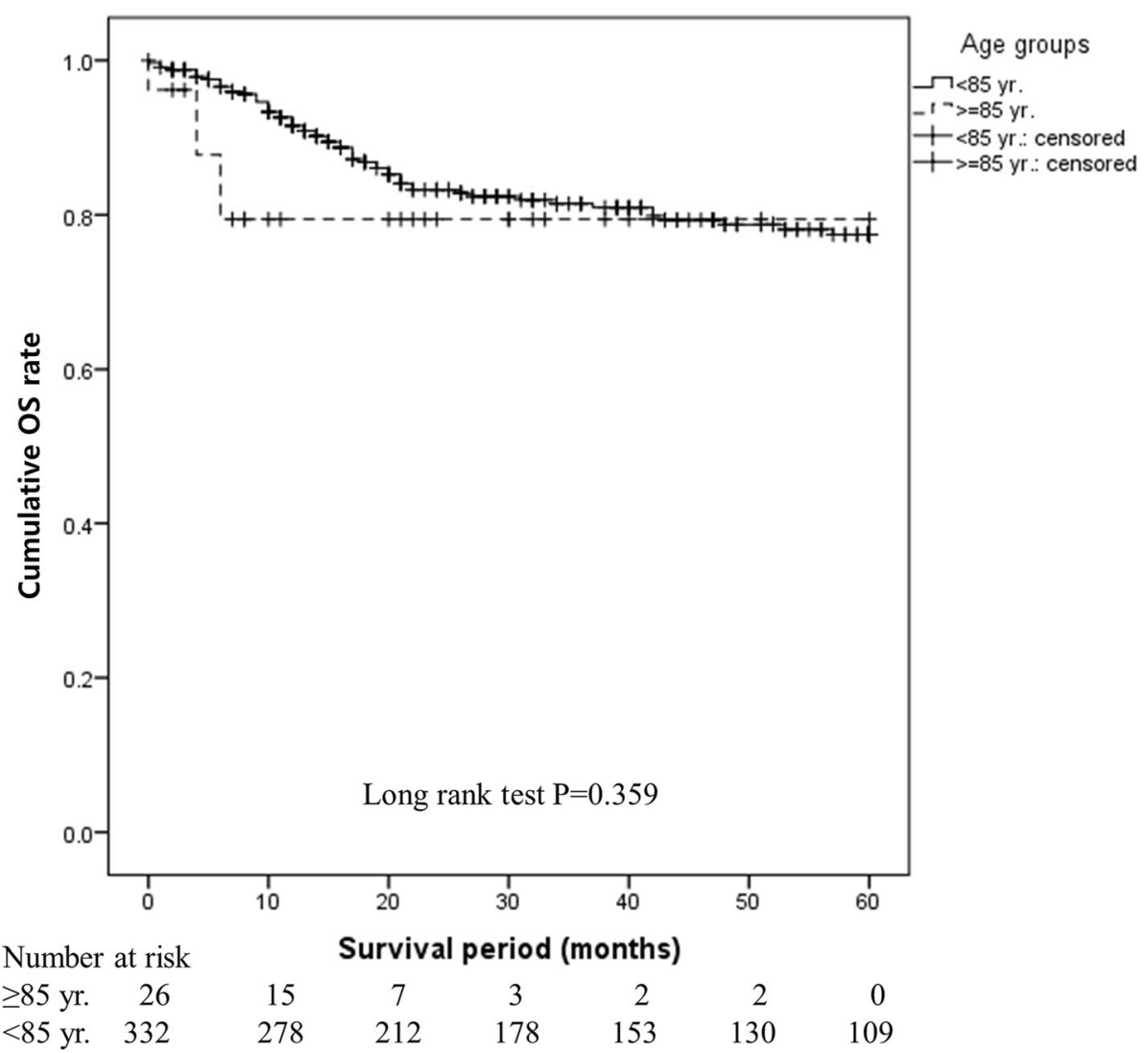

Fig. 1 Cumulative OS rate in patients with oral SCC in the $\geq 85$ years and $<85$ years groups. OS was shorter immediately after treatment initiation in the $\geq 85$ years group, but the 5 -year OS did not differ significantly between the $\geq 85$ years and $<85$ years groups $(80.8 \%$ vs. $82.2 \%, P=0.359)$

(HR: 1.125 , 95\% CI: $0.681-1.86, P=0.645)$ or multivariate analysis (HR: 0.900, 95\% CI: 0.529-1.529, $P=0.696$ ). Similarly, there was no difference in mortality based on sex or primary site. However, mortality was significantly higher in the $\mathrm{T} 3$ or more advanced disease group than in the T2 or earlier stage disease group in the univariate analysis (HR: 3.511, 95\% CI: 1.909-6.458, $P<0.001$ ) but not in the multivariate analysis (HR: 1.410, 95\% CI: $0.439-4.525, P=0.564)$. The risk of death was significantly increased in patients with lymph node metastasis in the univariate analysis (HR: 4.161, 95\% CI: 2.5316.842, $P<0.001$ ) and multivariate analysis (HR: 2.660, 95\% CI: $1.417-4.991, P=0.002)$ and in surgery patients in the univariate analysis (HR: 0.183 , 95\% CI: $0.108-$ $0.31, P<0.001$ ) and multivariate analysis (HR: 0.276, 95\% CI: 0.156-0.489, $P<0.001)$.

\section{Discussion}

In this study, there was no difference in the survival rate between the $\geq 85$ years and $<85$ years groups (Fig. 1 ) or between the operative and non-operative groups (Figs. 2 and 3), showing that age did not affect prognosis at our hospital. The OS rate was significantly higher in the operative group than in the non-operative group regardless of age $(P<0.001)$, clearly showing that operative treatment is superior to non-operative treatment. These findings suggest that radical treatment should be applied in $\geq 85$-year-old patients when possible and that surgery is desirable if $\geq 85$-year-old patients can tolerate the procedure. To the best of our knowledge, this is the first report to analyse oral SCC patients aged $\geq 85$ years, and it will be an especially useful clinical reference in the future.

We fully understand that some limitations of our study need to be considered. First, the $\geq 85$ years group contained only 26 patients. We are aware that the sample size of this study is too small for persuasive statistical analysis. A longer study period to collect the data of a sufficient number of patients aged $\geq 85$ years is needed. However, if we extend the review period to collect a sufficient number of patients, the therapeutic strategies and methods might change, and these changes might affect the outcome of the patients. Second, this study was a retrospective study in a single institution. Some might argue that a multiinstitutional study should be conducted. However, the OS of patients with oral cancer at all stages from several institutes seems to range from approximately 55 to $65 \%$ [11, 12], while the OS at all stages in our institute was $82.1 \%$ 


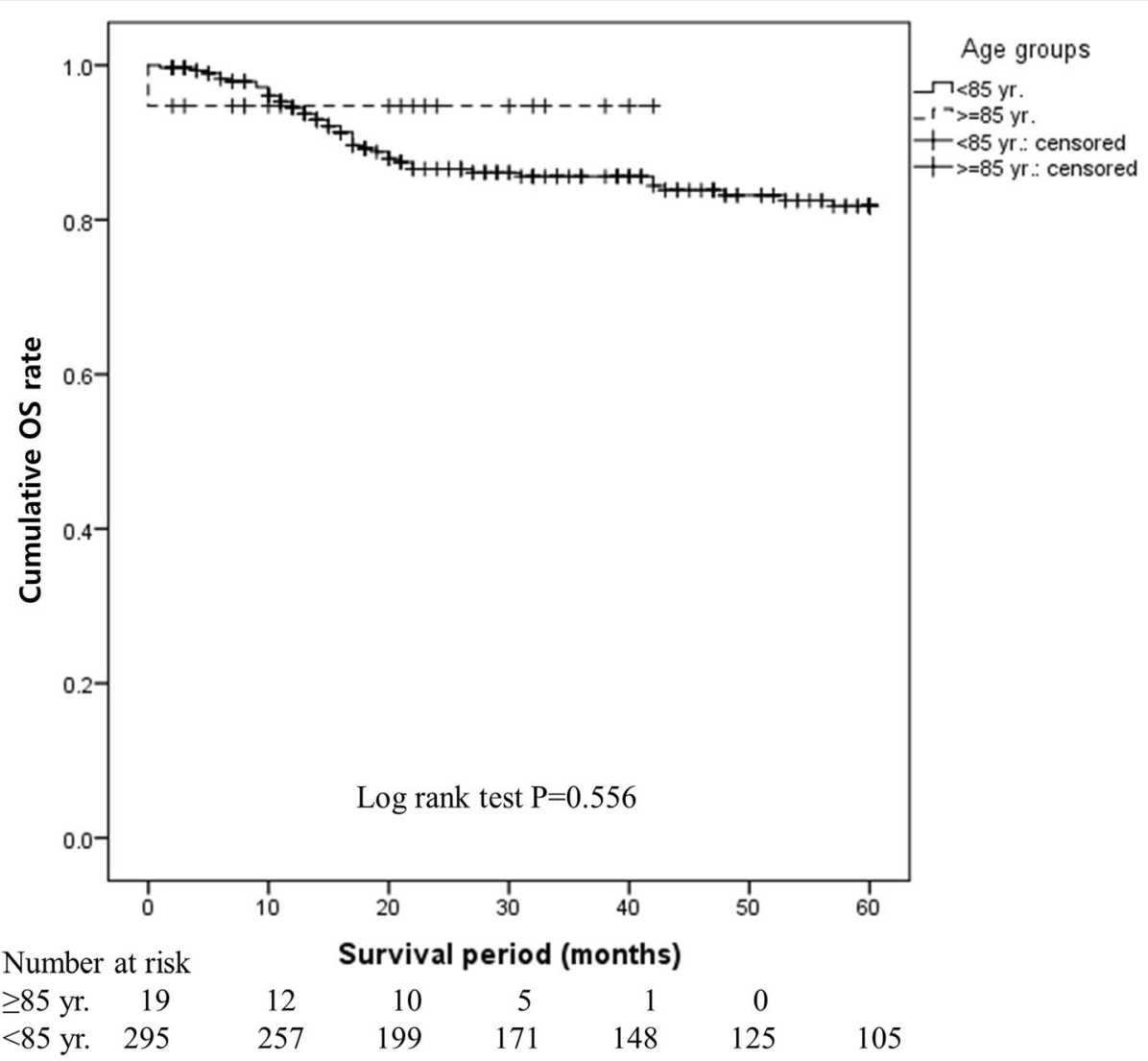

Fig. 2 Cumulative OS rate in patients with oral SCC treated with surgery in the $\geq 85$ years and $<85$ years groups. Figure 2 shows that OS in surgical cases did not differ significantly between the $\geq 85$ years and $<85$ years groups $(94.7 \%$ vs. $85.8 \%, P=0.556)$

(Table 2). Moreover, most institutions tend to avoid radical surgical treatment in patients aged $\geq 85$ years. Therefore, a multi-institutional study of $\geq 85$-year-old patients with oral cancer would be difficult to conduct. A strength of our study is that these results are from only a single institution that employed a consistent therapeutic strategy and had high medical standards during the study period because a single doctor (a chairman in our department at present) directed the treatment plans during this period. Additionally, variations in treatment levels and techniques, which are often observed in multi-institutional studies, did not occur.

The median age (66.1 years old) of patients with oral SCC in this study was higher than those reported in other countries $[8,9]$. The proportion of females $(73.1 \%)$ was significantly higher in the $\geq 85$ years group than in the $<85$ years group (Table 2 ). Similarly, the rate of females with oral SCC has increased with increased age in reports worldwide [7-9]. Our findings may be due to the higher life expectancy in females than in males in Japan (87.1 vs. 81.1 years) [4]) and the use of the threshold of 85 years in both sexes.
The rate of tongue cancer was significantly higher in patients aged < 85 years (Table 2), with a rate of $51.5 \%$, than in those aged $\geq 85$ years, whereas mandibular gingival cancer occurred most frequently in patients aged $\geq 85$ years, with a rate of $35.7 \%$. Pollom et al. reported similar findings that the frequent primary sites were tongue cancer and gingival cancer in younger and elderly patients, respectively [7]. In our study, the UICC TNM classification of local advancement was significantly more frequent in patients aged $\geq 85$ years than in patients aged < 85 years, whereas cervical lymph node metastasis was seen in a low number of these patients (Table 2). A similar tendency was shown in other reports [7, 8]. Awareness of a local tumour and visiting a hospital are likely to be delayed in elderly people, and this is considered to be a cause of local advancement, but there is no clear reason for the few number of cases with cervical lymph node metastasis. There was no significant difference in the final TNM classification due to age because of the conflicting results of $\mathrm{T} / \mathrm{N}$ classifications (Table 2). 


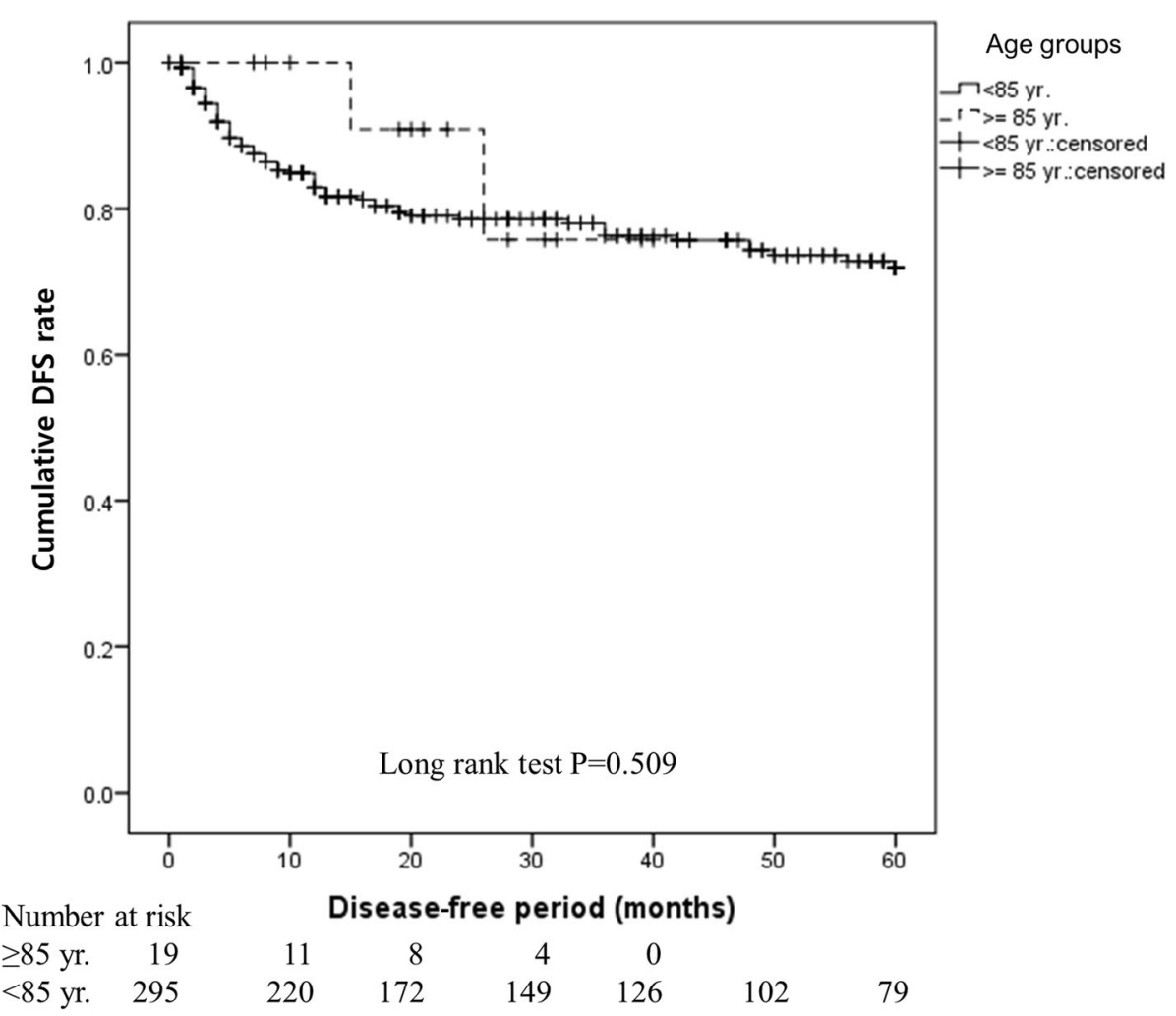

Fig. 3 Cumulative DFS rates in patients with oral SCC treated with surgery in the $\geq 85$ years and $<85$ years groups. Figure 3 shows that DFS in surgical cases did not differ significantly between the $\geq 85$ years and $<85$ years groups $(89.5 \%$ vs. $77.3 \%, P=0.509$ )

In our study, the OS rate decreased immediately after treatment initiation in the $\geq 85$ years group (Fig. 3). Of these patients, an 87-year-old female with T3N0M0 (stage III) tongue cancer suddenly died of acute heart failure 2 weeks after partial glossectomy, with no findings suggesting cervical lymph node metastasis. Vascularized free skin flap reconstruction was not performed to minimize surgical stress, and the wound was treated with primary closure. The operative time was $1 \mathrm{~h} 36$ min, and blood loss was minimal. Oral ingestion was started on the day following surgery, and the course of wound healing was favourable, but cardiopulmonary arrest occurred 7 days after surgery, and the patient died despite attempted resuscitation. A risk assessment of cardiac function was performed by a cardiologist before surgery, and a radiologist suggested that there was no cardiovascular contraindication for surgery. This case illustrates the difficulty of perioperative management in $\geq 85$-year-old patients.

Although the definition of elderly is unclear, $\geq 65$ years old is regarded as elderly in many countries [13]. This is based on a declaration by the World Health Organization (WHO) in 1965 that when people aged $\geq 65$ years exceed $7 \%$ of the population, society is regarded as an ageing society. The National Institute on
Aging of the National Institutes of Health $(\mathrm{NIH})$ classifies elderly patients into 3 groups: young old (65-74 years), older old (75-85 years), and oldest old ( $>85$ years) [14]. In some studies, half of new cancer patients not limited to oral cancer patients are $\geq 65$ years old [ 15 , 16]. The number of patients with oral SCC by year from the opening of our institute was calculated (Supplemental Fig. 1A). The median number of patients per year from 1974 to 2018 was 11 . After the opening our institute, there were only a few cases per year, but this stabilized at approximately 25 patients after 2005. The number of $\geq 85$-year-old patients per year has remained nearly constant since 2000 . The numbers of patients stratified by age until 2004 and in 2005 and thereafter were calculated (Supplemental Fig. 1B). After 2005, the number of patients in their $60 \mathrm{~s}$ increased. The peak age up to 2004 was 70-74 years old but shifted to 75-79 years old in and after 2005. Thus, the age of elderly patients with oral cancer in our institute is clearly increasing.

The selection of treatment for elderly patients requires the consideration of medical history, physical reserve capacity, physical and mental disabilities, and social background. Heterogeneity in conditions among individuals of the same age is a concern. The International 


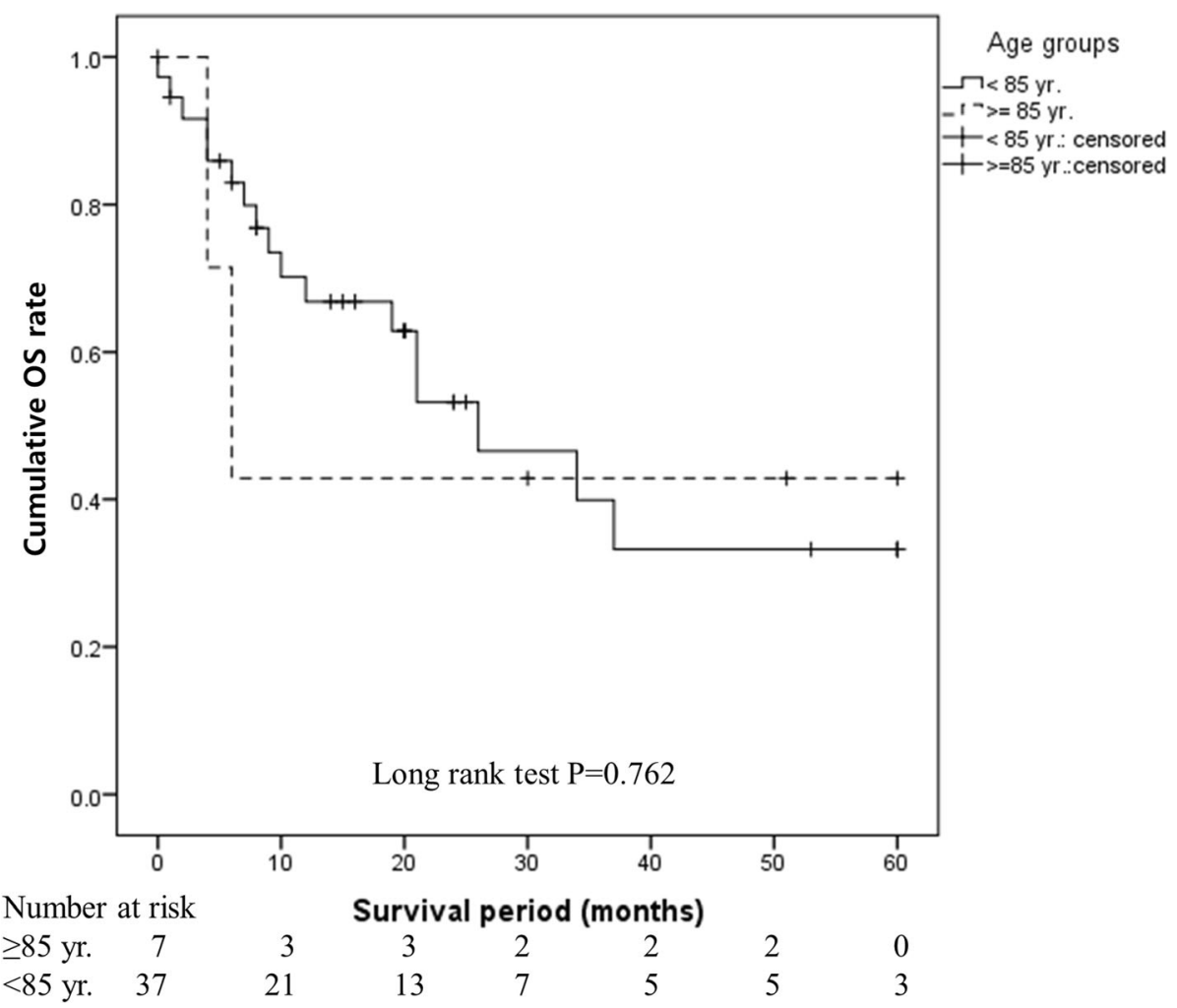

Fig. 4 Cumulative OS rates in patients with oral SCC treated without surgery in the $\geq 85$ years and $<85$ years groups. The OS in non-surgical cases did not differ significantly between the $\geq 85$ years and $<85$ years groups $(42.9 \%$ vs. $33.2 \%, P=0.762)$

Society of Geriatric Oncology (SIOG) and American Society of Clinical Oncology (ASCO) recommend the use of the Comprehensive Geriatric Assessment (CGA) in elderly cancer patients [13, 17, 18]. Many comparisons of oral cancer surgery in elderly and young patients have been reported. In an older large-scale retrospective study, the incidence of complications of surgery for cancer of the head and neck and the perioperative mortality rate were higher in elderly patients than in young patients, but the differences were small, and it was concluded that ageing should not restrict the application of surgery [19]. In a systematic review of free flap reconstruction in elderly patients with head and neck cancer, there was no difference in free flap engraftment, surgical complications, or mortality compared to these factors in young patients [20]. Non-operative treatments, such as radiation therapy and chemotherapy, are also reported to be uninfluenced by age $[5,6,8]$. Several recent cohort

Table 3 Mortality in patients with oral SCC between the non-operative and operative treatment groups during the 5-year follow-up period $(n=358)$

\begin{tabular}{|c|c|c|c|c|c|c|c|c|c|c|}
\hline \multirow[b]{3}{*}{ Sex, male vs. female } & \multicolumn{4}{|c|}{ Univariate analysis } & \multirow{3}{*}{$\frac{P \text { value }^{\text {a }}}{0.645}$} & \multicolumn{4}{|c|}{ Multivariable analysis } & \multirow{3}{*}{$\frac{P \text { value }}{0.696}$} \\
\hline & \multirow{2}{*}{$\begin{array}{l}\text { Crude HR } \\
1.125\end{array}$} & \multicolumn{3}{|c|}{$95 \% \mathrm{Cl}$} & & \multirow{2}{*}{$\begin{array}{l}\text { Adjusted HR } \\
0.900\end{array}$} & \multicolumn{3}{|c|}{$95 \% \mathrm{Cl}$} & \\
\hline & & 0.681 & - & 1.860 & & & 0.529 & - & 1.529 & \\
\hline Age group, $\geq 85$ years vs. $<85$ years & 1.529 & 0.612 & - & 3.821 & 0.364 & 1.172 & 0.395 & - & 3.482 & 0.775 \\
\hline Primary site, tongue vs. other ${ }^{b}$ & 1.015 & 0.622 & - & 1.658 & 0.951 & 1.478 & 0.888 & - & 2.460 & 0.133 \\
\hline T stage, $\mathrm{T} 3+\mathrm{T} 4 \mathrm{a}+\mathrm{T} 4 \mathrm{~b}$ vs. Tis $+\mathrm{T} 1+\mathrm{T} 2$ & 3.511 & 1.909 & - & 6.458 & $<0.001$ & 1.410 & 0.439 & - & 4.525 & 0.564 \\
\hline$N$ stage, $N 1+N 2 a+N 2 b+N 3 a+N 3 b$ vs. N0 & 4.161 & 2.531 & - & 6.842 & $<0.001$ & 2.660 & 1.417 & - & 4.991 & 0.002 \\
\hline Stage, stage $3+4 a+4 b+4 c$ vs stage $0+1+2$ & 4.201 & 2.139 & - & 8.252 & $<0.001$ & 1.541 & 0.388 & - & 6.118 & 0.539 \\
\hline Treatment, operation vs non-operation & 0.183 & 0.108 & - & 0.310 & $<0.001$ & 0.276 & 0.156 & - & 0.489 & $<0.001$ \\
\hline
\end{tabular}

SCC squamous cell carcinoma, $\mathrm{HR}$ hazard ratio, $\mathrm{Cl}$ confidence interval

${ }^{a}$ A Cox proportional hazard model was constructed using the variables with a $P$ value $<0.1$ in Table 2 . M stage was not included because the percentage of $M 1$ in those aged $<85$ years was zero

${ }^{\mathrm{b}}$ Other primary sites included the lower gingiva, upper gingiva, buccal mucosa, oral floor, lip, and palate 
analyses have suggested that the side effects and treatment effects of chemoradiation therapy (CRT) are tolerable and excellent, respectively, in elderly patients with head and neck cancer $[6,8]$. Huang et al. found no differences in the rates of treatment discontinuation and completion or treatment-related deaths between elderly and young patients receiving CRT [8]. In contrast, some reports illustrated difficulty in establishing indications for and the selection of treatment in elderly patients [10].

The treatment method might ultimately be decided by the patient's intention, but we should propose the optimum treatment plan based on the clinicopathological features of the tumour, the activities of daily living (ADL) and performance status (PS) of patients, patients' medical histories, support from patients' families, and patients' religious backgrounds. Although surgical resection of the tumour as the first choice treatment seems desirable, in cases in which surgery is likely to be tolerated, combinations of several novel molecular targeted therapies with surgery might further improve not only OS but also activities of daily living or quality of life after treatment in elderly patients with oral SCC. As a future task, it might be necessary not only to conduct the clinical study by increasing the number of patients aged $\geq 85$ years but also to establish a new protocol which could objectively evaluate the conditions and the backgrounds of elderly patients with oral cancer for choosing an optimal treatment method.

\section{Conclusions}

This study suggests that the prognosis of $\geq 85$-year-old patients with oral SCC was not inferior to that of $<85$ year-old patients. Patients aged $\geq 85$ years had a significantly lower rate of surgical therapy than those $<85$ years. The treatment of $\geq 85$-year-old patients requires careful consideration of the condition of the patient and the results of a risk assessment. It is necessary to further compile cases to perform a more detailed analysis, but we recommend the use of operative treatment even in $\geq 85$ years patients with oral SCC. It is desirable to use operative treatment as the first choice if psychosomatic and social conditions permit.

\section{Supplementary Information}

The online version contains supplementary material available at https://doi. org/10.1186/s12877-020-01902-3.

Additional file 1: Supplemental Figure 1A. Number of patients with oral SCC by year in our institute. Supplemental Figure 1B. Number of patients with oral SCC by age. The number of patients with oral SCC by year is shown in Supplemental Figure 1A. The median number of patients per year from 1974 to 2018 was 11 (minimum: 1, maximum: 41). After opening our institute, there were only a few cases per year, but this number stabilized at approximately 25 patients after 2005 (median: 25, minimum: 12 , maximum: 41). The number of patients aged $\geq 85$ years per year has remained nearly constant since 2000 . The numbers of patients by age until 2004 and in 2005 and thereafter are shown in Supplemental Fig. 1B. After 2005, the number of patients in their 60 s increased. The peak age was 70-74 years old (median: 66, minimum: 27, maximum: 97) up to 2004 but shifted to $75-79$ years old (median: 68, minimum: 16, maximum: 97) in and after 2005.

\section{Abbreviations}

SCC: Squamous cell carcinoma; OS: Overall survival; DFS: Disease-free survival; CRT: Chemoradiation therapy

\section{Acknowledgements}

Not applicable.

\section{Authors' contributions}

CF and HK firstly conceived the outline of this study. CF, SO, MT, THy, RK, YS, $\mathrm{TH}$, YK, AF, TW, YH, GH and HK contributed to study conception and design. MT and TH collected the clinical data, and CF and YH analysed data. CF and HK drafted the original manuscript and all authors commented on previous versions of the manuscript. All authors read and approved the final manuscript.

\section{Funding}

Not applicable.

\section{Availability of data and materials}

The datasets generated and analysed during the current study are not publicly available due ethical restrictions and patient confidentiality but are available from the corresponding author on reasonable request.

\section{Ethics approval and consent to participate}

The design of this study was approved by the Medical Ethical Research Committee of Dokkyo Medical University Hospital (approval ID R-22-12 J). None of the patients offered to be excluded and refused to publish.

Consent for publication Not applicable.

\section{Competing interests}

The authors declare no conflicts of interest.

\section{Author details}

${ }^{1}$ Department of Oral and Maxillofacial Surgery, Dokkyo Medical University School of Medicine, 880 Kitakobayashi, Mibu, Shimo-Tsuga, Tochigi 321-0293, Japan. ${ }^{2}$ Section of Dentistry, Oral and Maxillofacial Surgery, Sano Kosei General Hospital, 1728 Horigome town, Sano city, Tochigi 327-8511, Japan. ${ }^{3}$ Department of Public Health, Dokkyo Medical University School of Medicine, 880 Kitakobayashi, Mibu, Shimo-Tsuga, Tochigi 321-0293, Japan.

Received: 2 June 2020 Accepted: 12 November 2020

Published online: 20 November 2020

References

1. Ferlay J, Colombet M, Soerjomataram I, Mathers C, Parkin DM, Piñeros M, Znaor A, Bray F. Estimating the global cancer incidence and mortality in 2018: GLOBOCAN sources and methods. Int J Cancer. 2019;144:1941-53.

2. Brierley DJ, Gospodarowicz KM, Wittekind C. TNM classification of malignant Tumours. 8th ed. London: Wiley-Blackwell; 2017.

3. World Population Prospects: The 2017 Revision, Volume I: Comprehensive Tables. United Nations, Department of Economic and Social Affairs, Population Division. https://population.un.org/wpp/Publications. Accessed 30 Apr 2020

4. World Health Organization: World health statistics 2018: monitoring health for the SDGs, sustainable development goals. Geneva: World Health Organization. http://www.who.int/iris/handle/10665/272596. Accessed 30 Apr 2020.

5. Daly ME, Lau DK, Farwell DG, Luu Q, Donald PJ, Chen AM. Feasibility and toxicity of concurrent chemoradiation for elderly patients with head and neck cancer. Am J Otolaryngol. 2013;34:631-5. 
6. Michal SA, Adelstein DJ, Rybicki LA, Rodriguez CP, Saxton JP, Wood BG, Scharpf J, Ives DI. Multi-agent concurrent chemoradiotherapy for locally advanced head and neck squamous cell cancer in the elderly. Head Neck. 2012;34:1147-52.

7. Pollom EL, Chin AL, Lee NY, Tsai CJ. Patterns of care in adjuvant therapy for resected oral cavity squamous cell cancer in elderly patients. Int J Radiat Oncol Biol Phys. 2017;98:758-66.

8. Huang SH, O'Sullivan B, Waldron J, Lockwood G, Bayley A, Kim J, Cummings B, Dawson LA, Hope A, Cho J, et al. Patterns of care in elderly head-andneck cancer radiation oncology patients: a single-center cohort study. Int $J$ Radiat Oncol Biol Phys. 2011;79:46-51.

9. von der Grün JM, Martin D, Stöver T, Ghanaati S, Rödel C, Balermpas P. Chemoradiotherapy as definitive treatment for elderly patients with head and neck cancer. Biomed Res Int. 2018;2018:1-9.

10. Strom TJ, Naghavi AO, Trotti AM, Russell J, Kish JA, McCaffrey J, Otto KJ, Harrison LB, Caudell JJ. Increased acute mortality with chemoradiotherapy for locally advanced head and neck cancer in patients $\geq 70 y e a r s$. J Geriatr Oncol. 2017;8:50-5.

11. Chen SW, Zhang Q, Guo ZM, Chen WK, Liu WW, Chen YF, Li QL, Liu KU, Li $\mathrm{H}$, Ou-Yang D, et al. Trends in clinical features and survival of oral cavity cancer: fifty years of experience with 3,362 consecutive cases from a single institution. Cancer Manag Res. 2018;10:4523-35.

12. National Cancer Institute, US: The Surveillance, Epidemiology, and End Results (SEER) program of the National Cancer Institute, US. SEER Cancer Statistics Review (CSR) 1975-2016. https://seer.cancer.gov/csr/1975_2016/. Accessed 30 Apr 2020

13. Porceddu SV, Haddad RI. Management of elderly patients with locoregionally confined head and neck cancer. Lancet Oncol. 2017;18:e27483.

14. Parker SL, Tong T, Bolden S, Wingo PA. Cancer statistics, 1997. CA Cancer J Clin. 1997:47:5-27.

15. Muss HB. Cancer in the elderly: A societal perspective from the United States. Clin Oncol (R Coll Radiol). 2009;21:92-8.

16. Smith BD, Smith GL, Hurria A, Hortobagyi GN, Buchholz TA. Future of cancer incidence in the United States: burdens upon an aging, changing nation. J Clin Oncol. 2009;27:2758-65.

17. Wildiers $H$, Heeren $P$, Puts $M$, Topinkova E, Janssen-Heijnen MJG, Extermann M, Falandry C, Artz A, Brain E, Colloca G, et al. International Society of Geriatric Oncology consensus on geriatric assessment in older patients with cancer. J Clin Oncol. 2014;32:2595-603.

18. Mohile SG, Dale W, Somerfield MR, Schonberg MA, Boyd CM, Burhenn PS, Canin B, Cohen HJ, Holmes HM, Hopkinset JO, et al. Practical assessment and management of vulnerabilities in older patients receiving chemotherapy: ASCO guideline for geriatric oncology. J Clin Oncol. 2018;36: 2326-47.

19. Morgan RF, Hirata RM, Jaques DA, Hoopes JE. Head and neck surgery in the aged. Am J Surg. 1982;44:449-51.

20. Grammatica A, Piazza C, Paderno A, Taglietti V, Marengoni A, Nicolai P. Free flaps in head and neck reconstruction after oncologic surgery: expected outcomes in the elderly. Otolaryngol Head Neck Surg. 2015;152:796-802.

\section{Publisher's Note}

Springer Nature remains neutral with regard to jurisdictional claims in published maps and institutional affiliations.

Ready to submit your research? Choose BMC and benefit from:
- fast, convenient online submission
- thorough peer review by experienced researchers in your field
- rapid publication on acceptance
- support for research data, including large and complex data types
- gold Open Access which fosters wider collaboration and increased citations
- maximum visibility for your research: over 100M website views per year
At BMC, research is always in progress.
Learn more biomedcentral.com/submissions

